\title{
Dendritic Cells and T Lymphocyte Interactions in Patients with Lymphoid Malignancies
}

\author{
R. PYTLÍK, P. HOFMAN, L. KIDERYOVÁ, P. ČERVINKOVÁ, P. OBRTLÍKOVÁ, \\ J. ŠÁLKOVÁ, M. TRNĚNÝ, P. KLENER
}

First Department of Medicine, General University Hospital, Prague, Czech Republic

Received September 6, 2005

Accepted March 23, 2007

On-line available May 30, 2007

\begin{abstract}
Summary
Dendritic cell $(D C)$ vaccination is an attractive approach to the treatment of patients with lymphoid tumors. To evaluate its feasibility, we have tested the functional properties of DC and T-lymphocytes in patients with treated and untreated chronic lymphocytic leukemia (CLL) and follicular lymphoma (FL). Healthy volunteers were used both as controls and as a source of cells for allogeneic mixed leukocyte reaction (MLR). In these reactions, dendritic cells from both untreated and treated patients were comparable to dendritic cells from healthy volunteers. In all the untreated patients studied, autologous dendritic cells promoted the survival and proliferation of both CD4 and CD8 lymphocytes (though the proliferation response was much better in the CD4 subset), whereas only 3 out of 5 treated patients were able to mount this response with CD4 lymphocytes and 4 out of 5 with CD8 lymphocytes. In 3 out of 5 untreated patients, pulsing of DCs with tetanus toxoid promoted a better CD4 response than was achieved with unpulsed DCs, while none of 5 treated patients had an additional response after pulsing with tetanus toxoid. None of patients studied, either treated or untreated, had a better CD8 response to pulsed DCs than to unpulsed ones. During CD4 lymphocyte proliferation, more $\mathrm{CD} 4^{+} \mathrm{CD} 25^{\text {hi }}$ lymphocytes were generated in both treated and untreated patients than in healthy controls. Poor proliferation of cytotoxic cells and preferential proliferation of $\mathrm{CD} 4^{+} \mathrm{CD} 25^{\text {hi }}$ T-regulatory cells in response to self and/or foreign antigens might be one of the mechanisms responsible for immunosuppression and impaired tumor surveillance in patients with lymphoid malignancies.
\end{abstract}

\section{Key words}

Lymphoid malignancies - Mixed leukocyte reactions • T-regulatory lymphocytes

\section{Corresponding author}

R. Pytlík, First Department of Medicine, General University Hospital, U nemocnice 2, 12808 Praha 2, Czech Republic. Fax +420 22496 3117. E-mail pytlikr@seznam.cz

\section{Introduction}

Chronic lymphocytic leukemia (CLL) and follicular lymphoma (FL) are low-grade lymphoid malignancies, which are considered to be incurable by conventional therapy (Reiser and Diehl 2002, Polliack 2003). However, these diseases differ with respect to their influence on the host immune system. While immune deficiency is common in patients with CLL (Scrivener et al. 2003), the immune system of untreated patients with follicular lymphomas is largely intact. However, modern treatment for both diseases includes potent immunosuppressive drugs such as corticosteroids, purine analogues, monoclonal antibodies and high-dose therapy with stem cell transplant (Laurenti et al. 2004, Mackal et al. 2000), all of which may cause significant immunosuppression in patients who receive them.

Immunotherapy has long been viewed as an attractive approach to treatment of various incurable cancers, including low-grade lymphoid tumors. The general consensus is that if this approach is to be successful, it should be employed after the achievement of minimal residual disease (MRD) state, which means after conventional induction treatment. Several approaches to active immunization after conventional treatment of lymphoid malignancies were tried and clinical studies on this type of treatment have already been published or are going to be published (Dermime and Aljurf 2005) despite the fact that precise information about the potential immune defects caused by cytoreductive therapy are lacking.

As the most important cells in the antitumor response are antigen-presenting cells and T-lymphocytes, 
we studied the interaction between dendritic cells and $\mathrm{T}$ cells in both untreated patients with CLL and follicular lymphoma, and also in patients with these diseases in complete remission after chemotherapy or chemoimmunotherapy. The aim of our study was to ascertain whether the disease itself or its treatment causes functional damage to the dendritic cell-T cell axis and, if possible, to find which cells suffer a more severe insult.

\section{Methods}

\section{Study subjects}

Six patients with CLL and five patients with FL were studied (Table 1). Five of these were untreated and six were in complete remission at least six moths after completion of the treatment. Four of the six patients in complete remission had undergone high-dose chemotherapy and autologous stem cell transplant. Response criteria were assessed according to NCI-WG updated guidelines (Cheson et al. 1996) for CLL patients and according to NCI sponsored IWG guidelines (Cheson et al. 1999) for FL patients, respectively.

Ten members of the research team (three men and seven women, median age 31 years, range 21-50) without evidence of hematological, immunological or infectious disease were used as healthy controls. The study was approved by the local regulatory authority and all subjects gave written informed consent.

Dendritic cells, T-lymphocytes and mixed leukocyte reaction

Dendritic cells were generated from peripheral blood monocytes in a one-week protocol, as described previously (Spisek et al. 2001). A mononuclear fraction of peripheral blood leukocytes was obtained by centrifugation on Ficoll-Hypaque (Ammersham, Uppsala, Sweden) and monocytes were adhered overnight in six-well plastic plates (TPP, Switzerland). After washing off the nonadherent fraction, cells were cultured in RPMI 1640 medium (Gibco, Scotland) with $10 \%$ fetal calf serum for one week. GM-CSF (Schering-Plough, Ireland, $90 \mathrm{ng} / \mathrm{ml}$ ) and IL-4 (BD Biosciences, Germany, $20 \mathrm{ng} / \mathrm{ml}$ ) were added on the first and fourth days and poly I:C (SigmaAldrich, Germany, $50 \mathrm{ng} / \mathrm{ml}$ ) and TNF-alpha (BD Biosciences, Germany, $20 \mathrm{ng} / \mathrm{ml}$ ) were added $24 \mathrm{~h}$ before harvesting. In some experiments, tetanus toxoid (Chiron Vaccines, Germany, $5 \mu \mathrm{g} / \mathrm{ml}$ ) was added to immature dendritic cells on the fourth day. On the day of harvesting, samples of DCs were taken for flow cytometry studies and the remainder were used for allogeneic and/or autologous mixed leukocyte reactions (MLR).

Table 1. Patients' characteristics.

\begin{tabular}{lcccc}
\hline Patient code & $\begin{array}{c}\text { Age } \\
\text { (years) }\end{array}$ & $\begin{array}{c}\text { Sex } \\
\text { Leucocytes } \\
\text { at the time } \\
\text { of sampling } \\
\text { (x10/l) }\end{array}$ & $\begin{array}{c}\text { Lymphocytes } \\
\text { at the time of } \\
\text { sampling } \\
\text { (\%) }\end{array}$ \\
\hline $\begin{array}{l}\text { Untreated } \\
\text { patients }\end{array}$ & & & & \\
CLL1 & 55 & $\mathrm{~F}$ & 27.7 & 78.7 \\
CLL2 & 49 & $\mathrm{~F}$ & 44.7 & 75.0 \\
CLL3 & 54 & $\mathrm{~F}$ & 18.9 & 72.8 \\
FL1 & 47 & $\mathrm{~F}$ & 7.3 & 30 \\
FL2 & 75 & $\mathrm{M}$ & 18.3 & 64.5 \\
\hline CR patients & & & & \\
CLL4 & 60 & $\mathrm{M}$ & 6.7 & 32.2 \\
CLL5 & 62 & $\mathrm{M}$ & 4,4 & 30.0 \\
CLL6 & 60 & $\mathrm{M}$ & 6.3 & 53,2 \\
FL3 & 56 & $\mathrm{~F}$ & 4.9 & 20.0 \\
FL4 & 61 & $\mathrm{~F}$ & 5.5 & 29.2 \\
FL5 & 71 & $\mathrm{~F}$ & 2.8 & 29.4 \\
\hline
\end{tabular}

\begin{tabular}{|c|c|c|c|}
\hline \multicolumn{4}{|c|}{ Treatment details for CR patients } \\
\hline Patient code & $\begin{array}{l}\text { CR } \\
\text { number }\end{array}$ & Previous treatments & $\begin{array}{c}\text { Time from } \\
\text { last } \\
\text { treatment }\end{array}$ \\
\hline CLL4 & $1^{\text {st }} \mathrm{CR}$ & $\begin{array}{l}\text { Rituximab, } \\
\text { Fludarabine, } \\
\text { Cyclophosphamide, } \\
\text { ESHAP, BEAM + } \\
\text { ASCT }\end{array}$ & 30 months \\
\hline CLL5 & $1^{\text {st }} \mathrm{CR}$ & $\begin{array}{l}\text { Rituximab, } \\
\text { Fludarabine, } \\
\text { Cyclophosphamide, } \\
\text { ESHAP, BEAM + } \\
\text { ASCT }\end{array}$ & 22 months \\
\hline CLL6 & $1^{\text {st }} \mathrm{CR}$ & $\begin{array}{l}\text { Rituximab, } \\
\text { Fludarabine, } \\
\text { Cyclophosphamide, } \\
\text { ESHAP, BEAM + } \\
\text { ASCT }\end{array}$ & 8 months \\
\hline FL3 & $2^{\text {nd }} \mathrm{CR}$ & $\begin{array}{l}\mathbf{1}^{\text {st }} \text { line: CHOP, } \\
\text { Fludarabine- } \\
\text { Mithoxanthron } \\
2^{\text {nd }} \text { line: Rituximab, } \\
\text { ESHAP, BEAM + } \\
\text { ASCT }\end{array}$ & 12 months \\
\hline FL4 & $2^{\text {nd }} \mathrm{CR}$ & $\begin{array}{l}\mathbf{1}^{\text {st }} \text { line: CHOP } \\
2^{\text {nd }} \text { line: Rituximab, } \\
\text { ESHAP, BEAM + } \\
\text { ASCT }\end{array}$ & 36 months \\
\hline FL5 & $2^{\text {nd }} \mathrm{CR}$ & $\begin{array}{l}1^{\text {st }} \text { line: CHOP, } \\
\text { ESHAP } \\
2^{\text {nd }} \text { line: Rituximab, } \\
\text { Chlorambucil, } \\
\text { Etoposide, Prednison }\end{array}$ & 17 months \\
\hline
\end{tabular}

$M$ - male, F - female, ESHAP - Etoposide, AraC, Methylprednisolon, Cisplatin, CHOP - Cyclophosphamide, Adriamycin, Vincristine, Prednisolone, BEAM - BCNU, Etoposide, AraC, Melphalan, ASCT - autologous stem cell transplant. 
On the day when DCs were harvested, fresh CD4 and CD8 lymphocytes were obtained from the studied subjects by Ficoll-Hypaque centrifugation and immunomagnetic separation on MiniMACS or MidiMACS devices (Miltényi Biotech, Germany) according to the manufacturer's instructions. The purity of the CD4 and CD8 fraction was assessed by flow cytometry. The median purity of CD4 positive cells was $88.3 \%$ (range $63-98.7 \%$ ) and the median purity of CD8 cells was $81.6 \%$ (range 53.4-97.8\%). CD4 or CD8 lymphocytes (separately or in a 1:1 mixture) were mixed with dendritic cells in RPMI 1640 with fetal calf serum in 96-well plates in a ratio of 10:1 $\left(10^{5}\right.$ lymphocytes to $10^{4}$ dendritic cells per well). The total volume of the mixture was $300 \mu \mathrm{l}$ per well. Lymphocytes alone, dendritic cells alone or lymphocytes with tetanus toxoid only were used as negative controls. To differentiate between dendritic cell and T-cell dysfunction, patient lymphocytes were mixed with dendritic cells from healthy donors (and vice versa) in allogeneic MLR. Furthermore, autologous MLR with dendritic cells and T-lymphocytes from healthy volunteers were performed in some cases. All experiments were run in triplicate. After one week, the results of mixed lymphocyte reactions were evaluated by flow cytometry by a differential gating method, which is described below.

In each study subject, six sets of experiments were performed. The first set consisted of T-cell cultivation without the presence of antibody presenting cells (CD4 or $C D 8$, respectively). These experiments served as negative controls, against which other results were compared. The second set employed autologous MLR with monocyte-derived dendritic cells $(C D 4+D C$ or $C D 8+D C$ respectively). The third set consisted of autologous MLR performed with tetanus toxoid loaded dendritic cells $(C D 4+D C+T T$ or $C D 8+D C+T T)$. The fourth set was an allogeneic MLR with dendritic cells from different subjects (CD4 allo or CD8 allo respectively), which served as a positive control. The fifth set was another negative control and consisted of Tlymphocytes cultivated with tetanus toxoid, but without dendritic cells. As tetanus toxoid alone was not sufficient to induce survival or a proliferative response of $\mathrm{T}$ lymphocytes, the results of these tests did not differ from the cultivation of pure CD4 or CD8 lymphocytes and they are not shown in subsequent analyses. The sixth set of experiments consisted of dendritic cell cultivation without added lymphocytes. These wells generally contained very few living cells (mostly CD19 positive lymphocytes in untreated CLL patients or CD3 positive T-cells in samples from other subjects) and were used for estimation of the background noise (data not shown).

\section{Flow cytometry analysis}

The following monoclonal antibodies were used for the flow cytometric analysis of DCs and MLR: from DakoCytomation, Denmark: CD1a PE (clone NA1/34), CD3 FITC (clone UCHT1), CD4 PE (clone MT310), CD8 PE-Cy5 (clone DK25), CD11c FITC (clone KB90), CD14 FITC and PE (clone TUK4), CD16 PE (clone DJ130c), CD19 PE (clone HD37), CD25 FITC (clone ACT-1), CD45 FITC or PE (clone T29/44), CD45RA PE (clone 4KB5), CD45R0 FITC (clone UCHL1), CD71 FITC (clone Ber-T9), CD54 PE-Cy5 (clone 6.5B5), CD80 PE (clone 2D10.4), CD86 FITC (clone BU63), HLA-II FITC (HLA-DR, DP, DQ; clone CR3/43), and HLA-I PE (HLA-ABC; clone W6/32); from Pharmingen, Belgium: CD40 FITC (clone 5C3), and CD83 PE (clone HB15e); from Beckmann-Coulter (Immunotech, Czech Republic): ILT-3 PE-Cy5 (clone ZM3.8). 7-aminoactinomycin D (7-AAD, Sigma, Germany) was used for dead cell exclusion. All flow-cytometry measurements were performed on FACSCalibur (BectonDickinson, San Jose, CA) and analyzed on Summit ${ }^{\circledR}$ software v. 3.3 for Windows (kindly provided by DakoCytomation, Czech Republic). Positivity for a given antigen was defined as higher fluorescence intensity than that of $0.5 \%$ of the brightest cells in the isotype control. We decided to choose the percentage of positive cells as described above rather than the differences in mean fluorescent intensity $(\Delta \mathrm{MFI}=$ difference between MFI of the positive population and the control), as the fluorescent intensity peaks were rather wide, making this kind of comparison less informative.

\section{Differential gating as a method of MLR quantification}

The differential gating method has previously been described by our team as a simple and reproducible means of obtaining more information from the MLR than is possible with the use of the conventional ${ }^{3} \mathrm{H}$-thymidine incorporation assay (Obrtlíková et al. 2005). Precisely $100 \mu \mathrm{l}$ of the cellular suspension was taken from each well where MLR was performed, mixed with appropriate amount of antibody and diluted with $100 \mu$ l of phosphatebuffered saline (PBS without calcium and magnesium, Gibco, Scotland). In approximately $20 \%$ of cases, fluorescent microparticles (CytoCount ${ }^{\mathrm{TM}}$, DakoCytomation, Denmark) of known concentration were 

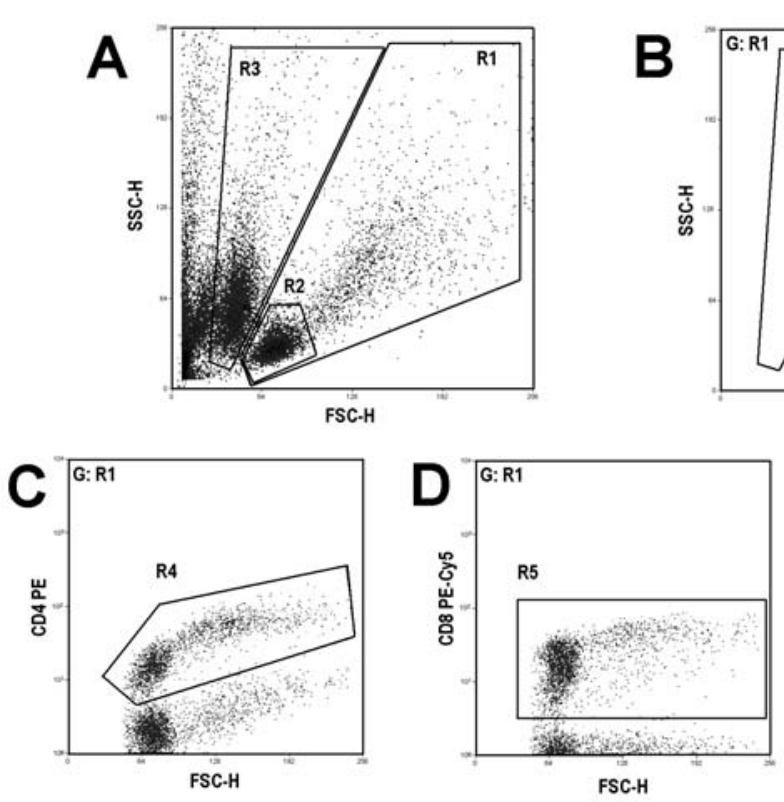

FSC.H
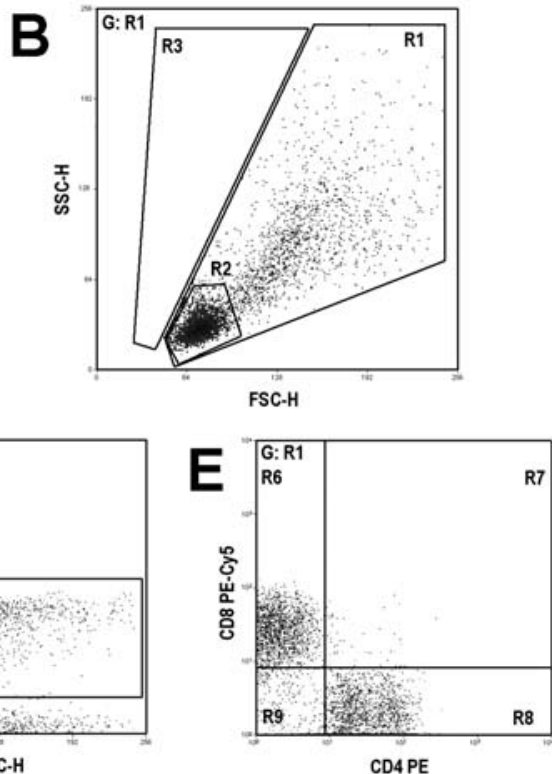

Fig. 1. The differential gating strategy. A - The basic forward scatter (FSC) and side scatter (SSC) distribution of proliferating $\mathrm{T}$ cells in the mixed leukocyte reaction. R1 gates living cells, and the population of resting cells with low forward and side scatter is gated separately (R2). The rest of the cells in R1 have the forward and side scatter properties of proliferating cells. The dead and apoptotic cells are gated in R3.

B - R1 gate is sampled, all other events are excluded. C - shows the population of CD4 positive cells in R1 gate (R4) on FSCxFL2 dot-plot. D - shows the population of CD8 positive cells in R1 gate (R5) on FSCXFL3 dot-plot. E - shows the distribution of CD4 cells (in quadrant R8) and CD8 cells (in quadrant R6) with a small number of double positive and double negative cells (quadrants R7 and $\mathrm{R}$, respectively). added to the sample instead of PBS to monitor sample volumes. These cross-validation experiments showed that $95 \%$ of samples did not differ by more than $1.2 \%$ from the target volume. Samples were run for $30 \mathrm{~s}$ on a FACSCalibur flow cytometer and all events were acquired. The number of events was adjusted for volume differences caused by adding of antibodies.

As can be seen in Figure 1A, the mainstay of this method is the differentiation between cells that are activated or proliferating and cells that are merely surviving in the culture. All living cells are displayed in the R1 gate on FSC-SSC scatter. These cells express appropriate lineage markers and do not accumulate 7-AAD. The subset of small cells with low side scatter is gated in R2. These cells did not express the proliferative marker CD71, most of them did not also express the interleukin-2 receptor CD25, and they were therefore consistent with small resting cells. On the contrary, the remaining population of cells in the $\mathrm{R} 1$ gate is characterized not only by large forward and side scatters, but also by strong CD71 expression and variable CD25 expression. Thus, the properties of these cells are consistent with activated and/or proliferating blasts. In R3, dead and apoptotic cells are displayed. They accumulate 7-AAD, but their DNA content is lower than in R2 cells (not shown). Ungated events, displaying very low forward scatter and variable side scatter, correspond to cellular debris and subcellular particles which are so small and damaged that they no longer contain any DNA. After the addition of up to three antibodies and excluding dead cells and debris (Fig. 1B), antigen expression and co-expression could be studied in appropriate fluorescent channels. As an example, the expression and coexpression of CD4 and CD8 is shown in Figs 1C-1E.

\section{Statistical analysis}

All experiments were done at least in triplicate. Analyses for individual patients and volunteers were done by comparing results from different sets of experiments. Global analyses were performed with average values for individual patients. For continuous variables, Student's $t$-tests for means or Student's $t$-tests for paired samples were used as appropriate. For categorical variables, Fischer's exact test was used. Correlations were calculated by Pearson's test. Values of $\mathrm{p} \leq 0.05$ (twosided) were judged to be statistically significant. All statistical analyses were performed with GraphPad Prism version 4.03 for Windows (GraphPad Software, San Diego, CA).

\section{Results}

Mature dendritic cells from patients with lymphoid malignancies differ only marginally from healthy controls

As can be seen in Figure 2A, there were no significant differences for most of the dendritic cellassociated antigens between patients and healthy controls. The only significant difference concerned the expression of CD83 (controls v. patients, $30.2 \%$ vs. $8.4 \%$, $\mathrm{p}=0.04$ ) and non-significant trend could be seen in CD80 


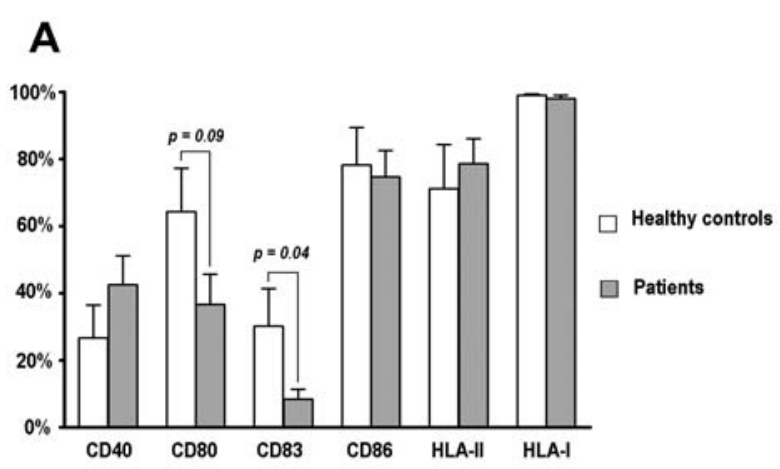

\section{B}
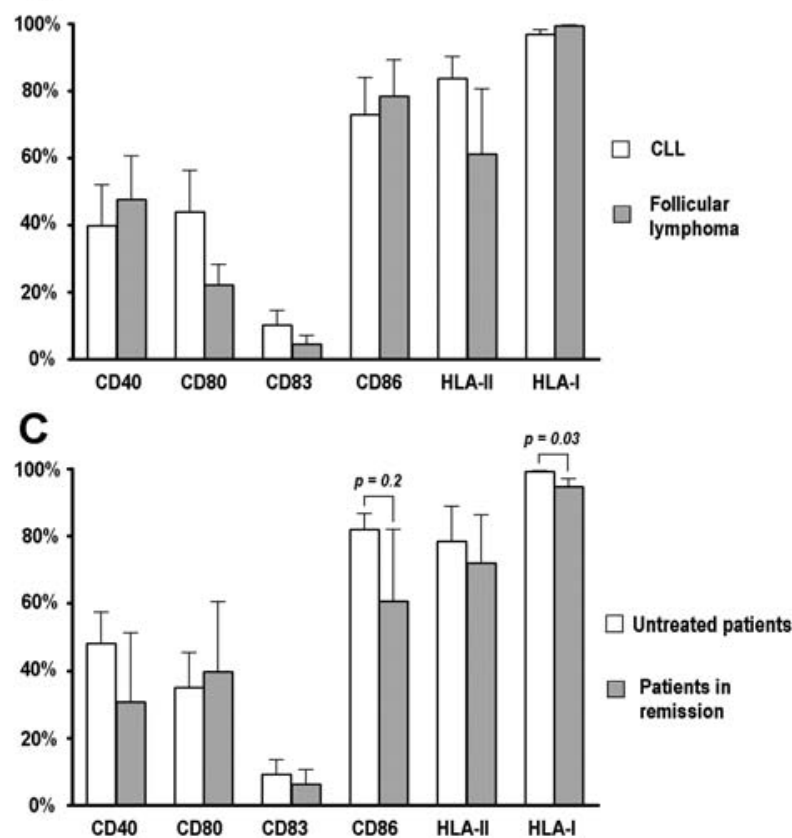

Fig. 2. Comparison of percentages of dendritic cells displaying characteristic surface antigens between different experimental groups. A - comparison between healthy controls (full bars) and patients (empty bars). More dendritic cells from healthy controls expressed CD83 $(p=0.04)$, while the trend towards higher expression of CD80 did not reach statistical significance $(p=0.09)$. B - comparison between CLL and FL patients revealed no differences in surface antigen expression. C - Dendritic cells from patients in remission displayed somewhat fewer costimulatory molecules than those from untreated patients, but this did not reach statistical significance. The only statistically significant difference was in expression of HLA-I antigen (see text).

expression (controls v. patients, $64.4 \%$ vs. $38.7 \%$, $\mathrm{p}=0.09)$.

There were no differences in antigenic profiles between patients with chronic lymphocytic leukemia and follicular lymphoma (Fig. 2B). On the other hand, treated patients expressed less HLA-I antigen on their surfaces than untreated patients ( $p=0.03$, Fig. $2 \mathrm{C}$ ). This difference was rather small in the absolute numbers of positive cells (99.3\% vs. $94.8 \%$ ), and did not translate into a difference in mean fluorescent intensity (mean $\Delta$ MFI 335.9 in untreated vs. 390.7 in treated patients, $p=0.67$ ).
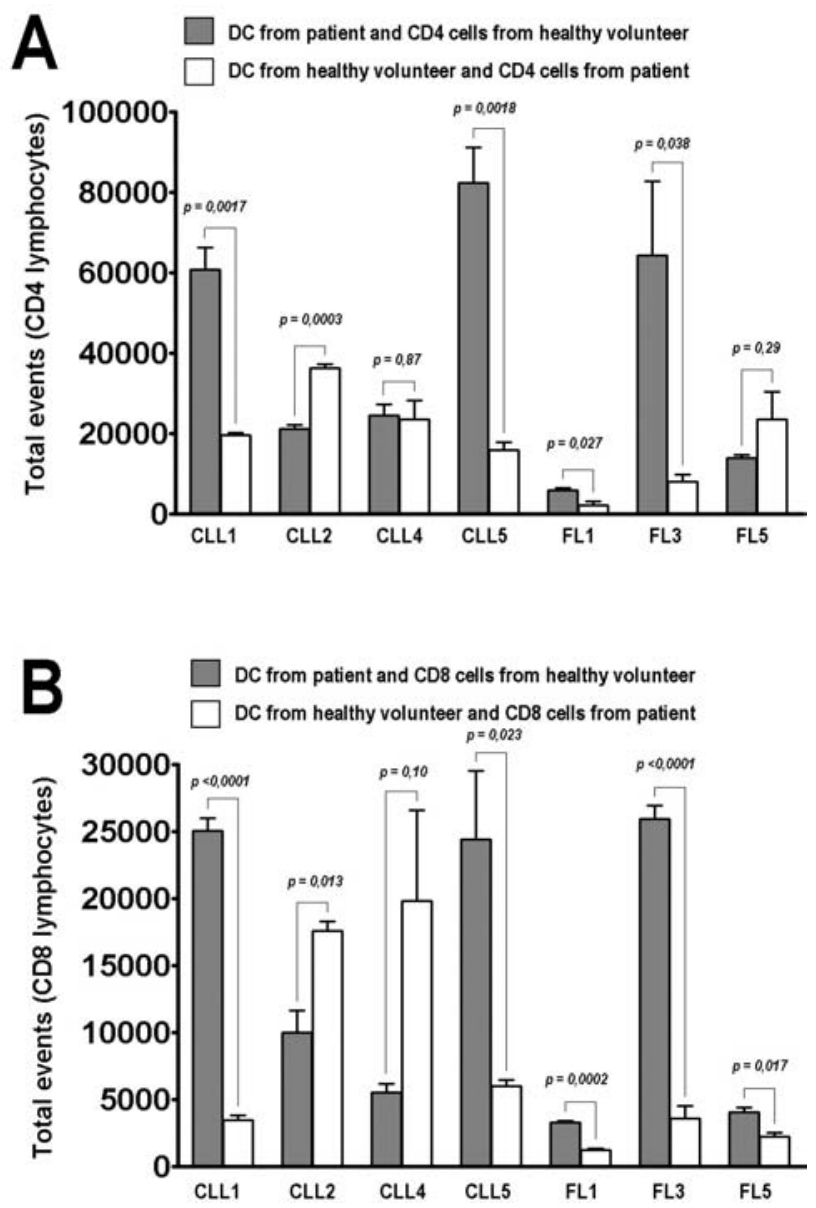

Fig. 3. Comparison of bidirectional mixed leukocyte reactions between patients and healthy volunteers. Results for CD4 cells (panel A) and CD8 cells (panel B) are shown separately. In most of the patient-control pairs, control T-cells proliferated better with patients' dendritic cells (full bars) than did patients' T-cells with healthy DCs (empty bars). For the same patient-control pairs, the results of mixed reactions with CD4 and CD8 cells were similar. Note significantly fewer events in the panel depicting the CD8 proliferative response.

\section{Dendritic cells are fully functional in patients with B-cell malignancies}

We performed bidirectional allogeneic mixed leukocyte reactions with pairs of patients and healthy volunteers. From seven test pairs with DCs and CD4 cells, CD4 cells of healthy volunteers proliferated better in four cases, worse in one case and the results were not significantly different in two cases (Fig. 3A). In two of the pairs, dendritic cells from lymphoma patients stimulated the proliferation of CD4 cells from healthy volunteers better than their own autologous DCs and in no case was the proliferation worse (data not shown). The same patient-control pairs gave essentially identical results for $\mathrm{CD} 8$ cells (Fig. 3B), with the exception that the total number of events acquired during the same time period was significantly lower (approximately one third 
to one half of the number of events compared with CD4 cells). This was not due to an artificial separation of CD4 or CD8 cells or larger numbers of CD4 cells in general, as better proliferation of CD4 cells was also observed in several experiments where CD4 and CD8 cells were mixed in a 1:1 ratio (not shown). These experiments proved that dendritic cells from patients with lymphoid malignancies can adequately stimulate T-lymphocytes from healthy donors, i.e. that dendritic cells from patients with lymphoid malignancies are fully functional.

Survival and proliferation of patients' CD4 and CD8 lymphocytes after addition of unpulsed and pulsed dendritic cells

After demonstration of the functionality of dendritic cells from patients with B-lymphoproliferative disorders, we were interested in how efficient these dendritic cells are in the induction of proliferation of autologous T-lymphocytes. In general, the addition of autologous unpulsed dendritic cells has increased the number of surviving and proliferating cells in both CD4 and CD8 lymphocyte subsets compared to control wells with CD4 or CD8 cells alone ( $p=0.007$ for CD4 lymphocytes, $\mathrm{p}=0.0008$ for $\mathrm{CD} 8$ lymphocytes). However, there were differences between untreated and treated patients. While addition of dendritic cells significantly increased the proliferation of both CD4 and CD8 lymphocytes in all the untreated patients, only three out of 5 treated patients showed an increased CD4 response and four of them an increased CD8 response. Moreover, while dendritic cells pulsed with tetanus toxoid produced better proliferation of CD4 lymphocytes than did unpulsed DCs in $60 \%$ of untreated patients, none of the treated patients' lymphocytes responded. Pulsing of dendritic cells did not produce better proliferation of CD8 lymphocytes in any of the untreated or treated patients. Although these results did not reach statistical significance on Fisher's test due to the small number of patients included, they suggest that cytotoxic treatment may reduce both the non-specific and specific proliferative responses in patients with lymphoid malignancies (Fig. 4).

Patients with lymphoid malignancies generate more $C D 4^{+} C D 25^{\text {hi }}$ cells than healthy controls

It has previously been shown that chronic lymphocytic leukemia and multiple myeloma patients have more circulating $\mathrm{CD} 4^{+} \mathrm{CD} 25^{\text {hi }}$ cells than healthy controls (Beyer et al. 2005, 2006). As this population

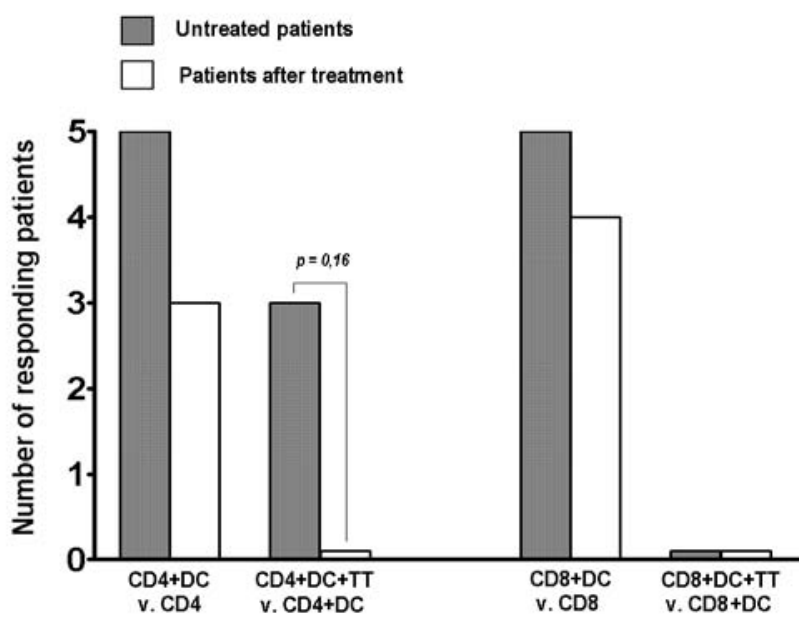

Fig. 4. Response of T-lymphocytes from treated and untreated patients in autologous MLR. Lymphocytes from treated patients showed less ability to respond to non-specific and specific antigenic stimulation. While in untreated patients, both CD4 and CD8 lymphocytes proliferated better with addition of autologous dendritic cells in all cases, treated patients' lymphocytes did not respond in several cases. Moreover, tetanus toxoid promoted an additional response (over unpulsed autologous DCs) only in CD4 lymphocytes of untreated patients (3 out of 5), while CD4 lymphocytes from treated patients and CD8 lymphocytes from both untreated and treated patients never responded.

contains T-regulatory cells which might suppress the autologous antitumor immune reaction, we were interested to investigate whether these cells are also produced in mixed lymphocyte reactions from lymphoma patients. The percentage of $\mathrm{CD} 4{ }^{+} \mathrm{CD} 25^{\mathrm{hi}}$ cells surviving after one week in control wells was similar in patients and healthy controls (mean $0.38 \%$ vs. $0.05 \%, \mathrm{p}=0.59$ ). In both types of autologous MLR (i.e. unpulsed and pulsed autologous DCs + CD4 lymphocytes), patients with follicular lymphoma and chronic lymphocytic leukemia produced more $\mathrm{CD} 4^{+} \mathrm{CD} 25^{\text {hi }}$ cells than healthy volunteers, but this trend did not reach statistical significance. However, in allogeneic MLR, the difference in percentages of $\mathrm{CD} 4^{+} \mathrm{CD} 25^{\mathrm{hi}}$ cells in patients and paired controls was highly significant (mean $3.03 \%$ vs. $0.65 \%$, $\mathrm{p}=0.0017$ ) (Fig. 5).

\section{Discussion}

In this small study, we have studied the relation between dendritic cells and $\mathrm{T}$ lymphocytes in patients with untreated and treated lymphoid malignancies. As model diseases, we chose chronic lymphocytic leukemia, in which profound immune deficiency can be seen even in untreated patients, and follicular lymphoma, where the immune system is fairly intact before the treatment is 

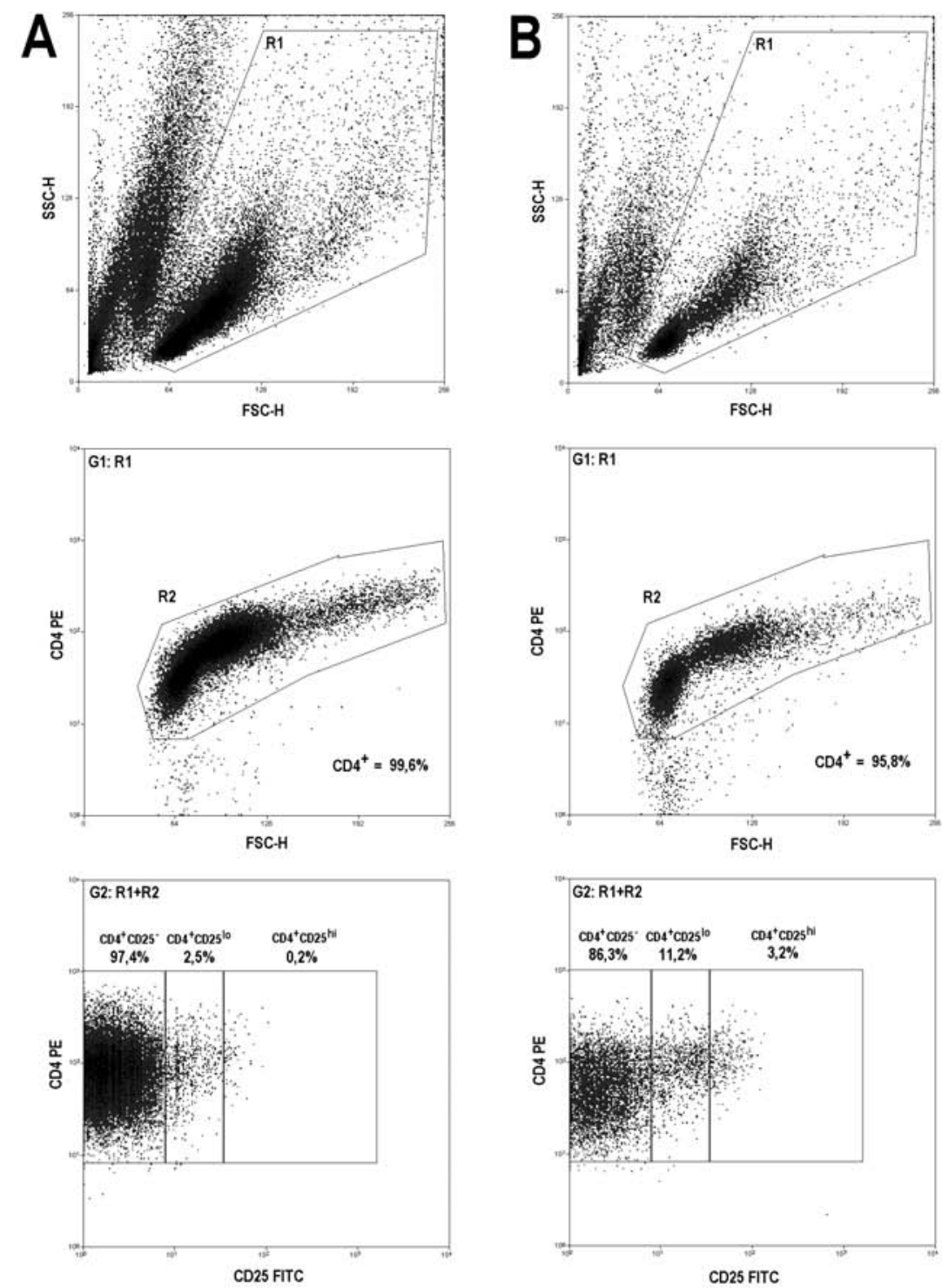

Fig. 5. Generation of $\mathrm{CD} 4^{+} \mathrm{CD} 25^{\mathrm{hi}}$ cells in a bidirectional allogeneic mixed leukocyte reaction. A representative experiment is shown on panel $\mathbf{A}$, which shows proliferation of healthy $\mathrm{CD} 4$ cells in response to dendritic cells from one of the patients, and on panel $\mathbf{B}$ which shows proliferation of this patient's CD4 cells in response to dendritic cells of the same healthy volunteer. On panel C, differences in production of $\mathrm{CD} 4^{+} \mathrm{CD} 25^{\text {hi }}$ cells between patients and controls in different types of autologous MLR and in paired allogeneic MLR is shown.

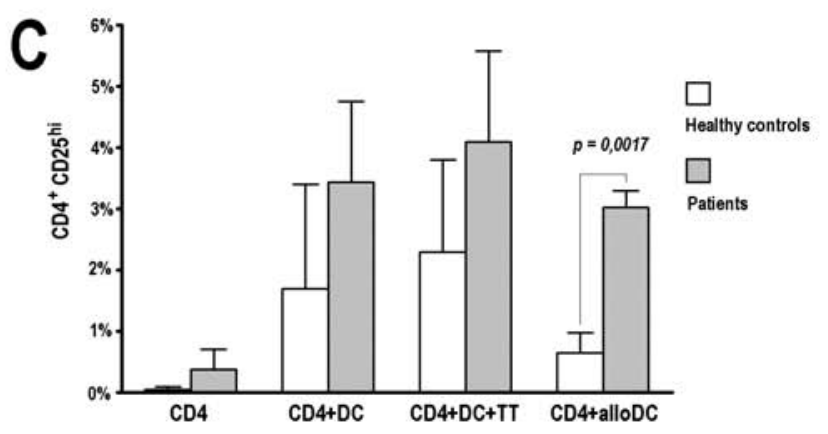

introduced. We performed two types of autologous mixed leukocyte reactions (MLR) - the non-specific MLR, where $\mathrm{T}$ lymphocytes were added to unpulsed dendritic cells, and the specific MLR, where immature dendritic cells were pulsed with tetanus toxoid before maturation and before the addition of $\mathrm{T}$ lymphocytes. Furthermore, we have performed bidirectional allogeneic MLR between dendritic cells from healthy controls and patients' $\mathrm{T}$ lymphocytes and vice versa.

Because of the small number of experiments, any conclusions from this study must be drawn with appropriate caution. However, our data are in most cases concordant with the data from previous studies and they highlight several points potentially important for the attempts to treatment of lymphoid malignancies with active immunization. 
First, we have shown that dendritic cells from patients with chronic lymphocytic leukemia and follicular lymphoma are fully functional before and also probably after treatment. Except for a smaller percentage of CD83 dendritic cells in lymphoma patients, the distribution of surface antigens was similar to DCs derived from healthy controls (Fig. 2A). Furthermore, there were only minor differences in surface antigen positivity between CLL and FL patients and between untreated patients and patients in complete remission (Figs 2B and 2C). This corresponds with the observation that in allogeneic MLR, both CD4 and CD8 lymphocytes from healthy controls were effectively stimulated by DCs from lymphoma patients (Table 1, Fig. 3). The fact that the antigen-presenting abilities of dendritic cells are preserved during the course of the disease and even after cytotoxic treatment is certainly reassuring, showing that immunization strategies in the state of minimal residual disease might be feasible.

On the other hand, we have observed diminished responsivity of autologous $\mathrm{T}$ cells in lymphoma patients in complete remission and, in certain cases, even before treatment. Surprisingly, in nonspecific autologous MLR (with unpulsed dendritic cells) we did not observe any differences between untreated CLL and FL patients, as both CD4 and CD8 lymphocytes responded in every patient studied. However, the nonspecific autologous MLR was not successful in several patients after treatment. Moreover, the specific autologous MLR (with tetanus toxoid pulsed DCs) with CD4 lymphocytes was successful in only 3 of 5 untreated patients compared to none of 5 treated patients and was not successful in a single case when immunomagnetically selected CD8 lymphocytes were used.

Several investigators have shown that dendritic cells might be important not only for the proliferation but also for the survival of resting T-cells. This can be important for maintaining the peripheral T-cell pool (Westermann et al. 2005), but it can also induce peripheral T-cell tolerance (Hawiger et al. 2001, Buchler et al. 2003). Moreover, there is increasing evidence that self-peptides from apoptotic autologous cells can be presented by dendritic cells in experimental systems similar to our own (Chernyscheva et al. 2002) and this can lead to expansion of $\mathrm{CD} 4^{+} \mathrm{CD} 25^{\text {hi }}$ regulatory cells (Cozzo et al. 2003), or to peripheral anergy induced by other mechanisms (Steinman et al. 2000, Wilson et al. 2004). These observations are also consistent with our own results which show that in bidirectional allogeneic
MLR, patients with lymphoid malignancies produce more $\mathrm{CD} 4{ }^{+} \mathrm{CD} 25^{\text {hi }}$ cells than paired healthy controls (Fig. 5). However, because in our experiments CD8 cells were purified before autologous MLR, this cannot explain the total failure of the specific autologous MLR with CD8 lymphocytes.

There are several other explanations for this observation. Our patients were neither boosted with tetanus toxoid before the specific autologous MLR reaction was performed nor were antibodies against tetanus toxoid measured. Thus, we cannot exclude the possibility that the poor results observed were caused by insufficient immunological memory, even if other workers have previously reported the effective use of tetanus toxoid at the concentration used in our system (Vuillier et al. 2001). Similarly, we have intentionally avoided the use of exogenous IL-2 to stimulate the proliferation response in the autologous MLR to allow for comparison between CD4 and CD8 response and at the same time, to avoid the preferential stimulation of $\mathrm{CD} 4{ }^{+} \mathrm{CD} 25^{\text {hi }}$ (T-regulatory) cells.

In summary, we have made several observations with potential importance for the active immunotherapy of lymphoid malignancies. First, autologous dendritic cells are fully functional in both untreated and treated patients and can be easily generated and expanded even after cytoreductive treatment. Second, both CD4 and CD8 lymphocytes can be easily expanded in autologous MLR in all untreated lymphoma patients, but only in a subset of patients in remission, even if a sufficiently long time has elapsed since the end of induction treatment. For the purposes of active immunotherapy, it may therefore be advantageous to collect a sufficient number of T-lymphocytes from lymphoma patients before the start of induction treatment and cryopreserve them for later use.

The relatively high percentage of $\mathrm{CD} 4^{+} \mathrm{CD} 25^{\text {hi }}$ cells generated in our experiments is in agreement with earlier reports on the presence of high numbers of these cells either in peripheral blood or in the tumor microenvironment of patients with a variety of lymphoid and solid tumors (Wolf et al. 2003, Marshall et al. 2004, Curiel et al. 2004, Beyer et al. 2005, 2006). Given the fact that these cells might be preferentially expanded after immunization with tumor-specific peptides or tumorantigen loaded dendritic cells, the generation of a large number of cytotoxic CD8 cells ex vivo and their adoptive transfer might be a preferable approach to immunization with tumor-antigen loaded dendritic cells. Definition of a 
cultivation system circumventing the specific CD8 unresponsiveness observed in our experiments and adjusting it for clinical grade production of sufficient numbers of T-lymphocytes might be an attractive alternative to in vivo vaccination strategies.

\section{Conflict of Interest}

There is no conflict of interest.

\section{Acknowledgements}

This work was supported with the grant IGA 8092-3 from Ministry of Public Health, Czech Republic and with the grant MSM 0021620808 from the Ministry of Education, Czech republic. Special thanks to Dr. Andrew Stewart for his help with the final version of the manuscript.

\section{References}

BEYER M, KOCHANEK M, KAMRUZH D, POPOV A, JENSEN M, ENDL E, KNOLLE PA, THOMAS KR, VON BERGWELT-BAILDON M, DEBEY S, HALLEK M, SCHULTZE JL: Reduced frequencies and suppressive function of $\mathrm{CD} 4{ }^{+} \mathrm{CD} 25^{\text {hi }}$ regulatory $\mathrm{T}$ cells in patients with chronic lymphocytic leukemia after therapy with fludarabine. Blood 106: 2018-2025, 2005.

BEYER M, KOCHANEK M, GIESE T, ENDL E, WEIHRAUCH MR, KNOLLE PA, CLASSEN S, SCHULTZE JL: In vivo peripheral expansion of naive $\mathrm{CD} 4^{+} \mathrm{CD} 25^{\text {high }} \mathrm{FoxP}^{+}$regulatory $\mathrm{T}$ cells in patients with multiple myeloma. Blood 107: 3940-3949, 2006.

BUCHLER T, HÁJEK R, KOVÁŘOVÁ L, MUSILOVÁ R, BOUŘKOVÁ L, ČECH Z, VÁŇOVÁ P, TUZOVÁ E, VIDLÁKOVÁ P, VORLÍČEK J, PENKA M: Low antigen-dependent activity of $\mathrm{T}$ cells after repeated stimulation using dendritic cells and expansion with interleukin-2. Neoplasma 50: 345-349, 2003.

CHERNYSHEVA AD, KIROU KA, CROW MK: T cell proliferation induced by autologous non-T cells is a response to apoptotic cells processed by dendritic cells. J Immunol 169: 1241-1250, 2002.

CHESON BD, BENNETT JM, GREVER M, KAY N, KEATING MJ, O'BRIEN S, RAI KR: National Cancer Institutesponsored Working Group guidelines for chronic lymphocytic leukemia: revised guidelines for diagnosis and treatment. Blood 87: 4990-4997, 1996.

CHESON BD, HORNING SJ, COIFFIER B, SHIPP MA, FISHER RI, CONNORS JM, LISTER TA, VOSE J, GRILLO-LÓPEZ A, HAGENBEEK A, CABANILLAS F, KLIPPENSTEN D, HIDDEMANN W, CASTELlinO R, HARRIS NL, ARMITAGE JO, CARTER W, HOPPE R, CANELlOS GP: Report of an International Workshop to standardize response criteria for non-Hodgkin's lymphomas. J Clin Oncol 17: 1244$1253,1999$.

COZZO C, LARKIN J III, CATON AJ: Cutting edge: Self-peptides drive the peripheral expansion of CD4 ${ }^{+} \mathrm{CD} 25^{+}$ regulatory T-cells. J Immunol 171: 5678-5682, 2003.

CURIEL TJ, COUKOS G, ZOU L, ALVAREZ X, CHENG P, MOTTRAM P, EVDEMON-HOGAN M, CONEJOGARCIA JR, ZHANG L, BUROW M, ZHU Y, WEI S, KRYCZEK I, DANIEL B, GORDON A, MYERS L, LACKNER A, DISIS ML, KNUTSON KL, CHEN L, ZOU W: Specific recruitment of regulatory $\mathrm{T}$ cells in ovarian carcinoma fosters immune privilege and predicts reduced survival. Nat Med 10: 942-949, 2004.

DERMIME S, ALJURF MD: Current advances, problems and prospects for vaccine-based immunotherapy in follicular non-Hodgkin's lymphoma. Leuk Lymphoma 46: 497-507, 2005.

HAWIGER D, INABA K, DORSETT Y, GUO M, MAHNKE K, RIVERA M, RAVETCH JV, STEINMAN RM, NUSSENZWEIG MC: Dendritic cells induce peripheral T cell unresponsiveness under steady state conditions in vivo. J Exp Med 194: 769-779, 2001.

LAURENTI L, PICCIONI P, CATTANI P, CINGOLANI A, EFREMOV D, CHIUSOLO P, TARNANI M, FADDA G, SICE S, LEONE G: Cytomegalovirus reactivation during alemtuzumab therapy for chronic lymphocytic leukemia: incidence and treatment with oral ganciclovir. Haematologica 89: 1248-1252, 2004.

MACKALL CL, STEIN D, FLEISHER TA, BROWN MR, HAKIM FT, BARE CV, LEITMAN SF, READ EJ, CARTER CS, WEXLER LH, GRESS RE: Prolonged CD4 depletion after sequential autologous peripheral blood progenitor cell infusions in children and young adults. Blood 96: 754-762, 2000. 
MARSHALL NA, CHRISTIE LE, MUNRO LR, CULLIGAN DJ, JOHNSTON PW, BARKER RN, VICKERS MA: Immunosuppressive regulatory $\mathrm{T}$ cells are abundant in the reactive lymphocytes of Hodgkin lymphoma. Blood 103: 1755-1762, 2004.

OBRTLÍKOVÁ P, PYTLÍK R, HOFMAN P, ČERVINKOVÁ P: Flow cytometric differential gating strategy for evaluation of T-lymphocyte survival and proliferation in mixed lymphocyte reaction with dendritic cells. Epidemiol Microbiol Imunol 54: 109-115, 2005.

POLLIACK A: Current therapeutic options for subgroups of chronic lymphocytic leukemia. Planning risk-adapted treatment according to recognized prognostic factors. Haematologica 88: 726-729, 2003.

REISER M, DIEHL V: Current treatment of follicular non-Hodgkin's lymphoma. Eur J Cancer 38: 1167-1172, 2002.

SCRIVENER S, GODDARD RV, KAMINSKI ER, PRENTICE AG: Abnormal T-cell function in B-cell chronic lymphocytic leukaemia. Leuk Lymphoma 44: 383-389, 2003.

SPISEK R, BRETAUDEAU L, BARBIEUX I, MEFLAH K, GREGOIRE M: Standardized generation of fully mature p70 IL-12 secreting monocyte-derived dendritic cells for clinical use. Cancer Immunol Immunother 50: $417-$ 427, 2001.

STEINMAN RM, TURLEY S, MELLMAN I, INABA K: The induction of tolerance by dendritic cells that have captured apoptotic cells. J Exp Med 191: 411-416, 2000.

VUILliER F, MALOUM K, THOMAS EK, JOUANNE C, DIGHIERO G, SCOTT-ALGARA D: Functional monocyte-derived dendritic cells can be generated in chronic lymphocytic leukaemia. Br J Haematol 115: 831$844,2001$.

WESTERMANN J, BODE U, SAHLE A, SPECK U, KARIN N, BELL EB, KALIES K, GEBERT A: Naïve, effector and memory T-lymphocytes efficiently scan dendritic cells in vivo: Contact frequency in $\mathrm{T}$ cell zones of secondary lymphoid organs does not depend on LFA-1 expression and facilitates survival of effector T cells. J Immunol 174: 2517-2524, 2005.

WILSON NS, EL-SUKKARI D, VILLADANGOS JA: Dendritic cells constitutively present self antigens in their immature state in vivo and regulate antigen presentation by controlling the rates of MHC class II synthesis and endocytosis. Blood 103: 2187-2195, 2004.

WOLF AM, WOLF D, STEURER M, GASTL G, GUNSILIUS E, GRUBECK-LOEBENSTEIN B: Increase of regulatory $\mathrm{T}$ cells in the peripheral blood of cancer patients. Clin Cancer Res 9: 606-612, 2003. 